\title{
Prevalence of Skin Diseases in Kavre District, Nepal
}

\author{
Karn $\mathrm{D}^{1}$, Khatri $\mathrm{R}^{2}$, Timalsina $\mathrm{M}^{3}$
}

${ }^{1}$ Lecturer, Department of Dermatology and Venereology, Dhulikhel Hospital, KUTH, Dhulikhel, Kavre

${ }^{2}$ Medical Officer, Sahid Memorial Hospital, Kalanki, Kathmandu.

${ }^{3}$ Dermatology Assistant, Department of Dermatology and Venereology, Dhulikhel Hospital , KUTH, Dhulikhel, Kavre

\section{Correspondence}

Dr. Dharmendra Karn

Department of Dermatology and Venereology,

Dhulikhel Hospital, KUTH,

Dhulikhel, Kavre,

e-mail : dddkarn@gmail.com

\begin{abstract}
Background

Skin is the major interface of human to the environment. It is the major susceptible organ for any disease. Wide prevalence of skin diseases in the community is a well established fact.

\section{Objectve}

The aim of this study is to determine the prevalence of skin diseases among the general population of Kavre District,Nepal .

\section{Methods}

This is a hospital based, retrospective study done among all the patients visiting Dhulikhel Hospital, Kathmandu University Teaching Hospital, in Dhulikhel, Kavre during the year 2007-2008 AD. Data were obtained from the hospital out-patient records and analyzed. The total number of patients who visited the hospital were 74,279 (male-30,809 female- 43,470), out of which 7374 (9.92\%), male 4155, female 3219, visited the Dermatology Department. Among this total study population now comparative study of the prevalence of skin diseases was performed based on sex, age and type of dermatological condition.
\end{abstract}

\section{Results}

The overall prevalence of skin diseases were $9.92 \%$ with slight higher rates seen among males ( $56.34 \%$ ) than females (43.65\%).Non-infective conditions, 6063 (82.22\% ) outweighed infective conditions 1311 (17.78 $\%)$, commonest one being the pigmentary disorders (32.56\%) and in the age group $16-35$ years old $(31.23 \%)$.

\section{Conclusion}

This study demonstrates that skin diseases are one of the most prevalent disease condition among the general population, representing a major public health problem.

\section{Keywords}

Prevalence, infective diseases, non-infective diseases. 


\section{Introduction}

Skin is the largest organ of the human body, a major interface between man and his environment and the most varied organ. Healthy and attractive skin plays a major role in most persons' self-esteem, and is a key component of the image they present to the outside world. The importance of healthy intact skin is beyond argument in the optimal physical functioning of the human body. Due to its exposure to the outside world and involvement in all most all of the systemic diseases, skin diseases is one of the most common health issue.

Worldwide the prevalence of skin diseases range from $14 \%$ to $87 \%^{1-2}$, population prevalence studies are in keeping with these figures, revealing an enormous burden of undiagnosed, untreated skin diseases, and Kavre District also cannot be exempt from it too.

Kavre district is a hilly district located at the distance of $21 \mathrm{kms}$ from Kathmandu, capital city of Nepal, located at the height of $318 \mathrm{mts}$ (kokhajor river) to $3018 \mathrm{mts}$ (Bethanchowk narayan dada). It has a population of $3,85,672$ with $1,88,972$ males and $1,96,725$ females ${ }^{1}$. The population in Kavre compromises of different ethnic groups including Brahmin, Chhetri, Newar, Gurung, Tamang, Tharu, Magar, Kami, Damai, Sarki, Bhojpuri and Limbu. There exists a considerable difference in traditions and the cultures of the different ethnic communities ${ }^{3}$.

To our best knowledge no study has been reported on the prevalence of skin diseases in this area.

\section{Methods}

This is a retrospective study carried out on the basis of outpatient visits in the Dermatology and Venereology Department of Dhulikhel Hospital, Kavre. The total sample size consisted of 7,374 patients (male 4,155 and female 3,219 ) of the year 2007-2008 AD. The details of the patient were obtained from the Outpatient registry book maintained by the department. Diagnoses of the patients were mostly done on the basis of clinical examination, investigations like punch biopsies and scrapings were also done. Our study also includes Sexually Transmitted Infections and Leprosy.

\section{Data analysis}

All the data was stored in an Excel file and descriptive statistics were performed. The standardized incidence was calculated for each disease variety, its relationships with the different age group and gender analyzed. The diseases were classified into infective type, which included fungal, viral, Arthropod borne, STIs, leprosy, and non infective type, which included Papulosquamous diseases, Appendegeal diseases, Connective tissue disorders, Inflammatory vasculitis, Bullous disorders, Pigmentary disorders.

\section{Results}

The overall prevalence of skin diseases was $9.92 \%$, among which $56.34 \%$ of the patients were males while $43.65 \%$ females. In the age group most of the patients were from 15 to 30 years of age $(52.84 \%)$ followed by below 15 years $(17.15 \%)$ (Figure 1). There were 6,063 cases $(82.22 \%)$ of non-infective skin diseases while only 1,307 (17.73 \%) were infective (Table 1 and 2). Among the non-infective diseases Pigmentary Disorders were the commonest (32.56 \%) followed by Appendegeal Disorders $22 \%$ (Table 1). Fungal diseases were the commonest infective disease condition accounting for the $5.47 \%$ of the cases (Table 2).

There were 127 cases of Sexually transmitted infections and 33 cases of Leprosy. We saw 5 HIV positive cases in this year. All of them were previously diagnosed cases, who came to us for the treatment of other co-morbid STIs, for which they received specific treatments. Later they were sent to Anti-Retroviral Centre, Kathmandu. Among the 33 cases of Leprosy received in the year 2007-2008, 5 were newly diagnosed cases. They were diagnosed on the basis of clinical examination, slit skin smears and skin biopsies.

\section{Figure 1 Study population by age groups}

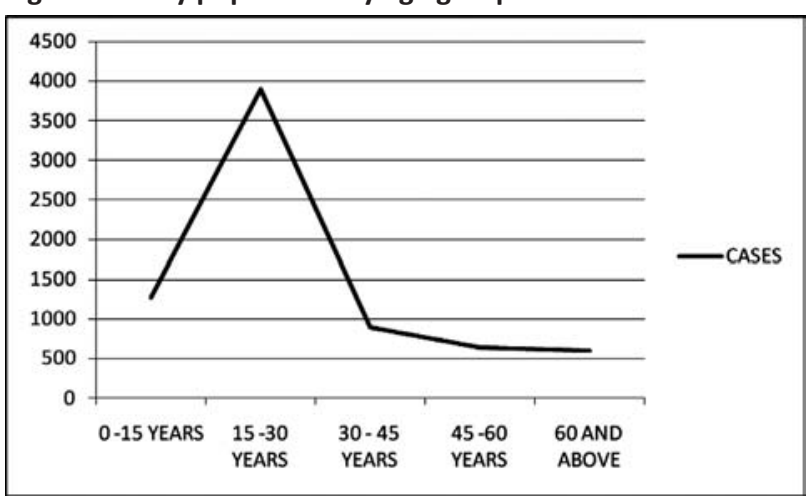

Table 1 Non-Infective Diseases

Total Number $=6063(82.22 \%)$

\begin{tabular}{|l|c|c|}
\hline & Number of cases & Percentage \\
\hline Papulosquamous Diseases & 681 & 9.2 \\
\hline Appendegeal Diseases & 1686 & 22 \\
\hline Connective tissue Diseases & 148 & 2.00 \\
\hline Inflammatory Diseases & 72 & 0.97 \\
\hline Bullous diseases & 372 & 5.04 \\
\hline Pigmentary Disorder & 2400 & 32.56 \\
Other Skin Diseases & 704 & 9.55 \\
\hline
\end{tabular}


Figure 2

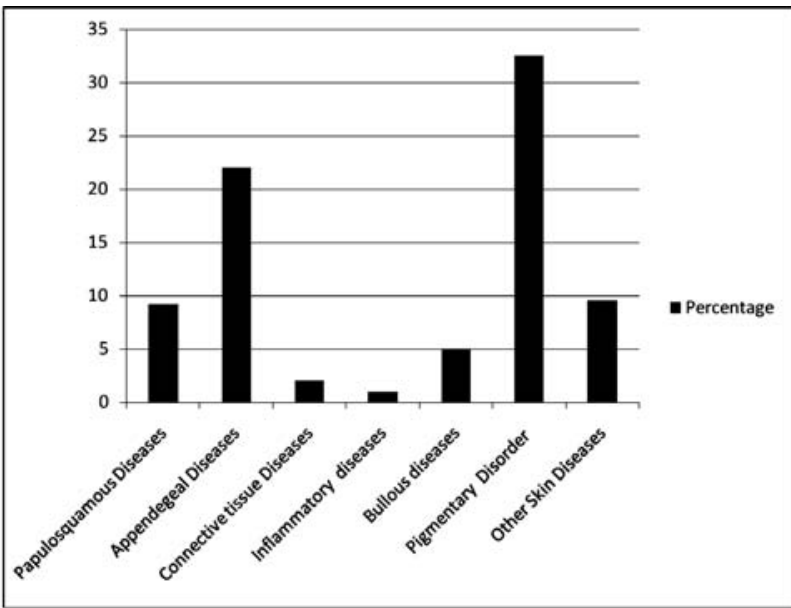

Types of Non-Infective Cases

Table 2 Infective Diseases

Total cases $=1,311(17.77 \%)$

\begin{tabular}{|l|c|c|}
\hline & Number of cases & Percentage \\
\hline Fungus & 403 & $5.47 \%$ \\
\hline Viral & 376 & $5.10 \%$ \\
\hline Bacterial & 135 & $1.83 \%$ \\
\hline Arthropod borne & 237 & $3.21 \%$ \\
\hline STI & 127 & $1.66 \%$ \\
\hline Leprosy & 33 & $0.44 \%$ \\
\hline
\end{tabular}

Figure 3

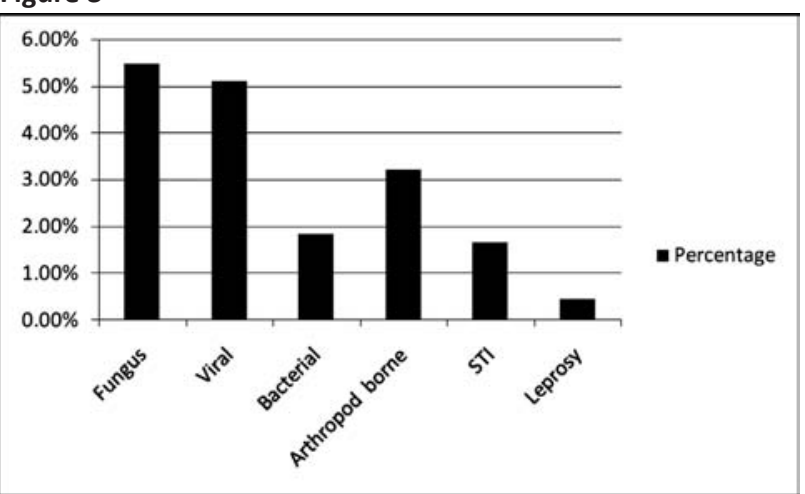

Types of Infective Diseases

\section{Discussion}

The prevalence of skin diseases in Kavre is seen to be slightly lesser than the standard prevalence rates ${ }^{2,4}$. This is not due to the low incidence of Dermatological conditions here but due to the ignorance, lower social and economical status of the people. Still skin conditions are taken lightly, ignored and they seek medical advices very late. The point prevalence of identifiable skin abnormalities was $62.2 \%$ (546 of 878 ) (with 95\% exact confidence intervals $58.9-65.4 \%$ ), as seen by a study done on the rural population of $\mathrm{Nepal}^{5}$.

Dermatology Department has the fifth highest flow of Outpatients in Dhulikhel Hospital. Nationally, Dermatological conditions rank sixth in the Ten Leading
Morbidity (Total New Visits as a Percentage of Total Population) in Out Patients Department ${ }^{6}$.

Similarly, the higher rates of male patients in the OPD can be justified by the fact that Nepal still being a male dominated society with men having more exposure to the outside world, more access to the hospital facilities while female population are reluctant to.

In the analytical study of the prevalence by age group, 15 to 30 years are the most active population. They are the bread earners in the Nepali community. They are supposed to be working outside the house. And the people in this age group are also self conscious about their looks, skin and personalities. So the highest prevalence among this population is self justified.

The most striking finding of our study is the higher prevalence of non- infectious diseases, it is firstly because Dhulikhel Hospital itself and the Dermatology Department as well serves as the tertiary referral centre in Nepal. Many of the common disorders are being treated first in the primary health centres, Outreach health posts (of Dhulikhel Hospital itself) and even by the pharmacists as Over The Counter drugs. Second,because of the availability of Laser Therapy in Dhulikhel Hospital, first of its kind in Nepal and its wide popularity among the general population throughout the country.

\section{Conclusion}

This study demonstrates that skin diseases are one of the most prevalent disease conditions among the general population, representing a major public health problem. Adequate measures should be taken from the National Policy levels to the grass root community levels to mitigate the problem.

\section{References}

1. Central Bureau of Statistics, Government of Nepal, 2001.

2. Rook A, Savin JA, Wilkinson D, et al. Rook Textbook of Dermatology. Oxford: Blackwell Publication Ltd 1998.

3. Introduction of Kavre District, www.kavreli.com

4. Crissey JT, Parish LC. The Dermatology and syphiology of the Nineteenth Century. New York

5. Walker SL, Shah M, Hubbard VG, Pradhan HM, Ghimire M. Skin disease is common in rural Nepal: results of a point prevalence study. http://www.ncbi.nlm.nih.gov/ sites/entrez

6. The Department of Health Services, Nepal Government, Annual Report 2064/65; Ten Leading Morbidity (Total New Visits as a Percentage of Total Population), by Development Region and Ecological Zone, FY 2064/65 (2007/2008)

7. Jha A.K. and Gurung D, Seasonal variation of skin diseases in Nepal: A hospital based annual study of out-patient visits. Nepal Med Coll J. 2006;8(4):266-8 